Psychology of Language and Communication 2017, Vol. 21, No. 1

DE DE GRUYTER

OPEN

DOI: $10.1515 /$ plc-2017-0015

IRINA OVCHINNIKOVA ${ }^{1,2}$, ANNA PAVLOVA ${ }^{3}$

${ }^{1}$ Perm State University

${ }^{2}$ Haifa University

${ }^{3}$ University of Mainz

\title{
LEXICAL SUBSTITUTION AND PARAPHASIA IN ADVANCED DEMENTIA OF THE ALZHEIMER TYPE
}

\begin{abstract}
The paper presents the case study of lexical selection in Alzheimer-type dementia. Lexical substitutions in poem recitation and conversations of a Russian speaker, who suffered Alzheimer-type dementia, were analyzed on the background of the lexical retrieval and slip-of-the-tongue phenomena. The classification of the substitutions is worked out on the basis of the links between a target word and its substitutions. The current context plays an essential role as natural priming for a substitution in a poem recitation. Some words have predisposition to be lost; the units belong to the figurative language or to the category of infrequent lexemes. In conversation, the patient masked failures by referring to the circumstances and appealing to the sense of humor. Positive emotions facilitate recollecting of words, involved in the description of real-life events, due to the relatively spared nondeclarative memory. The changes in the substitutions and paraphasias categories between $\mathrm{AD}$ stages are statistically significant.
\end{abstract}

Key words:Alzheimer disease, slips of the tongue, lexical substitution, verbal associations, dementia

\section{Introduction}

\section{Goals and expectations}

Substitutions in spontaneous speech reveal interconnections in the mental lexicon and mechanisms of lexical selection and semantic retrieval during speech generation. A word replacing a lexeme, which was forgotten or escaped from

Address for correspondence: Anna Pavlova, Johannes Gutenberg-Universität Mainz, 76726 Germersheim An der Hochschule 2, Germany. E-mail: anna.pavlova@gmx.de 
the tip of the tongue (TOT), is connected with a current context or a speaker's "inner context." The criteria of semantic retrieval from the mental lexicon in the process of speech production were found and described by Brown and McNeil as a way to search a word in a TOT state (Brown \& McNeil, 1966). However, the speaker is often not able to recognize a substitution in his/her own speech. The speaker monitors the search of the lexeme in the TOT state, while the substitution is produced unconsciously. So, the criteria relevant to the TOT phenomenon do not cover all substitutions in spontaneous speech or texts recitation.

Substitutions represent a common feature of verbal behavior. In neurolinguistics, different types of substitutions are described from the diagnostic perspective (Ferraro \& Wilmoth, 2013). However, research of substitutions in communication and text recitation by aging people, including those with advanced dementia and Alzheimer's disease (AD), appears to be insufficient. The specific peculiarities of speech processing in AD patients were described in connection with the brain damage (Cera, Ortiz, Bertolucci, \& Minett, 2013; Schecker, Kochler, Schmidtke, \& Rauh, 2014). Mild AD and moderate AD patients performed the Boston Naming Test with a statistically significant deviation compared to a control group as well as to each other (Silagi, Bertolucci, $\&$ Ortiz, 2015). The main peculiarities of speech generation in AD patients were found; nevertheless, the spontaneous verbal behavior of the patients differs from the carefully controlled test performance. The types of substitution/paraphasias and supporting strategies that the AD patients use to retain an appropriate "social façade" need to be characterized on the basis of the everyday communication and text recitation. Our case study aims to cover the gap.

\section{Approach to the lexical substitutions/paraphasias research}

As usual, a substitution appears in sentence production when the lexical access is restricted by some obstruction and a speaker fails to select a proper unit in the mental lexicon, making attempts to retrieve a word from long-term storage into working memory and to withstand the influence of the current context thanks to inhibitory control. The structure of the long-term storage of verbal information, which is referred as mental lexicon, is determined by frequency, time of word acquisition, and the diversity of its associations with other words (Baayen, Milin, \& Ramscar, 2016). Associations in the mental lexicon affect word processing in short-term memory (Stuart \& Hulme, 2000). Therefore, associative links work as mediators in lexical access and retrieval, as well as in the process of generating the utterance in working memory. The target word associations often spring out as its paraphasic substitutions. However, in $\mathrm{AD}$ wide spreading cortical atrophy affects semantic long-term memory as well. Associations as substitutions in AD probably acquire specific features based on a patient's individual experience.

The capacity of working memory is limited; nevertheless, in communication an individual needs to perform several tasks and solve several problems at 
the same time. This multitasking generates grounds for interference. The more similar units are involved in problem solving, the higher the probability of different problem solutions becoming confused or overlapped. Thus, during production of an utterance an individual overcomes the interference, spending his/her resources of focus and self-control. In cognitive disorders (as AD) the resources and inhibitory control are poor; hence, individuals with AD produce more different substitutions, especially paraphasias, than a normal speaker. Interference with the current context will probably be more noticeable in $\mathrm{AD}$ patients.

To study the substitutions, we need to deal with three linguistic parameters: (1) a substitution, (2) a target word, and (3) a current context. A substitution reflects some connections with (2) and (3), as well as with the individual's psychological state and mood. It is obvious that the semantic similarity with the target word foregrounds a substitution, and phonetic parallels in the current context lead to paraphasias. According to (Silagi, Bertolucci, \& Ortiz, 2015), the number of semantically unrelated verbal paraphasias significantly increased in a group of moderate $\mathrm{AD}$ patients, while appearance of phonetically similar substitutions for a target word did not match statistical criteria in ANOVA (Silagi, Bertolucci, \& Ortiz, 2015, p. 425, Table 1). Severe brain damage causes more problems in object recognition and word recollection. However, it is still unclear:

- What kind of semantic similarity between the target word and its substitutions is important for activating a substitute?

- How does semantic similarity compete with verbal associations to the target word?

- What parameters are crucial for substitution activation?

- Are there any specific types of substitution during a poem recitation in AD patients?

Thus, we will clarify the questions and will consider the strategies for lexical retrieval in Alzheimer-type dementia on the basis of a case study. The original substitutions classification is worked out on the basis of the material. We argue that the substitutions in $\mathrm{AD}$ :

- Represent a set of normally encountered ways to substitute a target word;

- Reveal the support of nondeclarative long-term memory;

- Express specific difficulties in lexical retrieval and selection during poem recitation due to the damage of the encoding, storage, and retrieval processes of semantic long-term memory, while in spontaneous speech the substitutions are also determined by the insufficiency of the inhibitory control. 


\section{Material and methods}

\section{Material for the case study}

Our research of the AD patient's language behavior is conducted on the grounds of continuous everyday longitudinal observation of the patient over four years (January 2012 - October 2016). The material includes records of spontaneous speech and poem recitations (more than 20,000 units in dialogues and declamation of poems as everyday exercises; the patient's speech samples are represented in a quarter of the units). A family member, a caregiver of the patient, recorded the speech in a friendly environment ${ }^{1}$. The diversity of the material allows for clarification of different strategies in lexical retrieval in the speech generating process versus text reproduction. The poem recitations reveal triggers for a substitution more clearly, since the original target word is obvious.

Individual LA (age 86 - 90) was a Russian speaker; before her retirement, she worked as an English language teacher in Saint Petersburg. AD was recorded in the patient's hospital chart by her neurologist (Atos Klinik, Heidelberg, Germany) for the first time in October 2009: "3.10.2009. Dementia, Alzheimer's type (?). Mild cognitive impairment; MMSE 21.0. Diabetes mellitus, Morbus Paget; Hyperacusis in both ears. The patient feels fine; she mentions her memory difficulties, becoming more forgetful, but considers her forgetfulness as a natural aging effect. A patient's caregiver observes the intensifying memory loss in the last three years. According to the caregiver, the patient is losing her ability to concentrate. Two-sided sonographic examination of the supra-aortic: normal blood flow to brain."

One year later the diagnosis was confirmed: "28.09.2010. Dementia, Alzheimer's type (amnestic). The patient complains of forgetfulness, but claims being able to perform activities of daily living (ADL). Meanwhile, the caregiver explains that for a year the family members had been performing ADLs for the patient. The patient had been leaving home accompanied by the caregiver or another person. Psychopathology: memory deficits; attempt to retain an appropriate 'social façade'; reduction in social activities and social-communication abilities; feels sleepy."

In 2011, 12.04.11, the neurologist confirmed the diagnosis as "moderate $\mathrm{AD}$, the Subcortical Vascular Encephalopathy in progress ${ }^{2}$. Ataxia (impaired coordination of walking) within Vascular Encephalopathy." However, the patient endeavored to mask her memory loss and lack of focus by appealing to the sense of humor and empathy. She had been joking, shifting the responsibility for communicative failures to her interlocutors, and referring to her individual circumstances as an excuse.

Authors are responsible for the selection of spontaneous speech samples.

2 Vascular Dementia coexists with AD according to (Jellinger, 2013) 
The caregiver began to record the patient's speech and observations in January 2012, during daily memory training exercises and conversations with family members. The patient's condition worsened; in 2013 she needed permanent assistance in her ADLs. Nevertheless, the patient was still able to perform simple work like washing, peeling and cutting vegetables in the kitchen. She was also able to knit simple things, but needed someone to help her count stitches. Meanwhile, LA's walking coordination was impaired; she faced difficulties in keeping walking equilibrium.

In August 2014 (17.06.2014) the diagnosis was "Alzheimer-type dementia; Parkinson's disease (MMSE 12.0). The patient requires 24-hours supervision, also her language behavior deteriorated; she had been forgetting to eat and drink, lost the feeling of hunger and thirst; intensified disorientation and memory loss."

In February 2015 (24.02.2015), the patient suffered AD and Parkinson's disease. The damage provoked poor understanding of the current context and lack of ability to reason. In a letter to the family doctor, the neurologist recommended intensive professional care in a nursing home and mentioned: "As Alzheimer's disease progressed, the symptoms of the secondary parkinsonism, the hypokinesia and muscular dystonia have aggravated." The patient passed away in January 2017.

This case study of the AD patient analyzes language behavior in the situation of the complicated development of the disease that reflects the diversity of disease manifestation in aging, when changes in the person's condition and behavior impede distinguishing of the influence of the different factors.

\section{Methods}

We studied lexical substitutions in the AD patient compared to common mistakes in lexical selection using discourse analysis. Semantic similarity between the target word and its substitution is described as semantic proximity in the lexicon; two words are similar if they belong to the same node or hierarchy in the ontology (Slimani, 2013). Associations to the target words from the current context were verified in the Russian Associative Thesaurus (RAT ${ }^{3}$ ). We examined subcorpuses of Russian National Corpus ${ }^{4}$ for word frequencies. Being aware of the ambiguity of word frequency (Baayen, Milin, \& Ramscar, 2016), we took into consideration the frequency of the precise grammatical form of the word in the adequate subcorpus, the Poetry Corpus or the Corpus of Spoken Russian, respectively.

First of all we will describe and characterize the LA's substitutions and paraphasias in the aspect of their semantic similarity and associative connections to target words. Then we will consider LA's speech deficit. In the description of our results we will offer classification of the substitutions in AD patients. After

\footnotetext{
http://www.tesaurus.ru/dict/dict.php

4 http://ruscorpora.ru/en/index.html. Frequencies were verified on December 16, 2016.
} 
that we will discuss the difference in the substitutions in her spontaneous speech and poem recitations on the background of the studies on speech behavior in $\mathrm{AD}$ patients.

\section{Results of the analysis: types of the substitutions}

\section{Semantic similarity between the target word and substitutions}

Synonyms and Hypernyms as substitutions. Synonyms represent the most widespread way to replace a word in communication, fiction and poetry. LA switched to the frequent synonyms of target words when reciting poems. In the recitation of Marshak's translation of the English ballad "The Little Woman and the Peddler", she replaced a rare verb with trivial ones:

(1) (02.2013) У самой дороги поспать / уснуть прилегла (instead of взоремнуть)

Close to the road to sleep / to fall asleep laid down (instead of to take a nap $)^{5}$

The verb 'ycнymb (to fall asleep)' is a synonym, while 'nocnamb (to sleep)' represents the category name for the target action. Our patient sometimes replaced words by their Hypernyms / Category names in the process of poem recitation, as 'nocnamb (to sleep)' in (1). In the LA's spontaneous speech, Hypernyms rarely appeared as substitutions.

Co-hyponyms as substitutions. A Co-hyponym substitutes a target word when a speaker searches for a precise name but fails to access a proper lexeme or to learn the difference between Co-hyponyms. Every Co-hyponym of a target word provokes the risk of meaning shift or misrepresentation. Co-hyponyms appeared in LA's speech in three variants. First of all, she switched to a more frequent lexeme from the target word category:

(2) $(09.2012$; 02.2013) и дуб сквозь иней зеленеет, (instead of ель) and an oak through hoarfrost shows green, (instead of a fir)

In the Poetry Corpus the noun ' $\partial y \sigma$ (oak)' occurs in 1630 contexts, while the target word 'ель (fir)' is mentioned in 839 sentences. The word and images of heavy oaks predominated in Pushkin's poetry, as well as in the Russian folk tradition. LA selected the noun according to some vague idea how it should be in the poetry and, probably, owing to the association with a well-known oak from the first lines of Pushkin's "Ruslan and Lyudmila."

Secondly, LA mixed up two rare words from the periphery of her lexicon. LA was reciting the line 'The coachman sits huddled upon his box, In a sheepskin coat and a scarlet sash" from Pushkin's "Eugene Onegin" as:

\footnotetext{
5 We provide literal translation for poem recitation, while LA's spontaneous speech was translated from Russian into English correctly. For every example the date follows the number.

$6 \mathrm{http} / / /$ lib.ru/LITRA/PUSHKIN/ENGLISH/onegin_j.txt (last accessed 16.04.2017)
} 
(3) (09.2012) в тужурке, в красном колпачке (instead of в тулупе, в ... кушаке $)^{7}$

in a mess jacket, in a red hood.

Russian folklore contains special connotations of the target word 'myлyn (sheepskin coat)' and its substitution 'тужурка (теss jacket)' as well; the first one is associated with peasants and coachmen, the latter is connected to commissars and revolutionary sailors in October 1917. The noun 'тужурка (mess jacket)' was more common in LA's experience, who had lived and worked in Saint Petersburg before she moved to Germany in the very beginning of the new century.

Thirdly, a Co-hyponym springs up into a sentence according to the consonance and alliteration (Vitevitch \& Luce, 2016). LA produced a lot of this kind of paraphasia. Thus, Pushkin's Eugene Onegin:

(4) (04.2014) легко лезгинку танцеввал (instead of мазурку) easy lezginka danced (instead of mazurka)

LA unconsciously preferred the Caucasian folk dance lezginka, owing to the consonance with the previous adverb 'легко (easy)'.

Hyponyms as substitutions. When selecting a Hyponym, a person intends to express his/her idea precisely. The target word appears to be irrelevant to the individual's intention, so he/she prefers its Hyponym. Participants of communication often use Hyponyms as an instrument of self-correction, which sometimes slides off into hypercorrection. Nevertheless, LA produced a Hyponym once in a poem recitation, but several times spontaneously without any difficulties or hesitation to emphasize her idea:

(5) (09.2012) “Так это потому, что я ленивая. Нет, скажем так, помягче: с ленцой."

"So it is because I am lazy. No, let's say softly, I am a slacker."

LA made an attempt to emphasize how she perceived herself. She selected a common attribute for laziness; however, changed her mind and referred to herself with her charming sense of humor. The new characteristic connected to the target as a more concrete expression with additional semantic features.

\section{Associations as substitutions/paraphasias}

Associations are caused by a variety of reasons, according to psychological mechanisms for information processing. Associative thesauruses contain sets of the common associations essential for a language and its culture; the associations aggregate a network of words in the national language, which reveal lexical interconnections relevant to the mental lexicon of the language speakers. Thus, associative links are easy to evoke by a word, as well as by different parameters

В тулупе is represented in 196 contexts from the Poetry Corpus, в тужурке - in 59. 
of the social interaction. Mild and even moderate AD patients struggle to find the semantically relevant word among its associations to substitute the target; nevertheless, matching semantic criteria is a hard task for the patients.

Associations to the target word. Associations semantically connected to the target words are very helpful in any case of the slip of the tongue because they mark a semantic area of the target. LA often replaced a forgotten word by its associations if she remembered the meaning of the missing target. Reciting Tatyana from "Eugene Onegin", LA forgot an infrequent target word and mentioned a frequent substitution":

(6) (05.2015) В лесу в деревне все вам скучно (instead of в глуши) In the forest in the village all to you drearily (instead of at a remote place).

The set of associations for the Russian word 'лес (forest)' contains the reaction 'глухой лес (godforsaken forest)', which is connected by the root morpheme to 'глушь (remote place)'. The substitution of an infrequent word with fuzzy semantics by a frequent one occurs regularly in poem recitation, but they are not typical of LA's conversation.

Associations semantically connected to the left context. Sometimes LA was not able to recollect the meaning of the target word or something drew away her attention while producing a sentence. In this situation, the left context of the sentence worked as natural priming for the next speech unit. Recollecting a poem of Korney Chukovsky, LA found a hint in the previous line while she was making attempts to access the target word:

(7) (09.2012) Муха по полю пошла, Муха зернышко нашла (instead of денежку)

A fly on the field went, A fly a grain found (instead of a coin)

The word ' поле (field)' triggered an association more suitable to the context: a grain would be more likely to be found in the field than a coin. The related word 'зернышко' appears in RAT to the word 'field'. The target word is not semantically connected with the left context; the compensation of the missing semantic relations determines a distinctive feature for the substitution in comparison with the TOT phenomenon. In such cases, individuals attempt to fulfill the syntactic position in the sentence without remembering the meaning of the target word.

Associations semantically connected to the right context. Planning an utterance, a speaker grounds on a 'fuzzy semantic cloud' (Vygotsky, 1934) and looks for appropriate lexical units to verbalize his/her intention. The recent modeling of speech comprehension and production tends to consider at least two

В лесу was mentioned in 1114 contexts from the Poetry Corpus, в глуии - 370 .

9 http://www.tesaurus.ru/dict/dict.php (last accessed 20.11.2016) 
types of mental representations to be involved in natural language processing (Zwaan, 2016). According to Zwaan, symbolic and sensorimotor representations mutually constrain each other while an individual attempts to understand the message and to react relevantly. Thus, the semantic cloud needs to be structured on the basis of individual experience and knowledge; the sensorimotor representation provides the basis for structuring and restructuring, being concrete and detailed. Abstract concepts serve as mediators or pointers in the memory for integrating upcoming/already processed information into the sensorimotor simulation. Hence, an individual can label some content of the text by the abstract concept and store it this way in order to reactivate it when needed. So, the abstract concept makes Vygotsky's semantic cloud more distinct. Since apperception allows for predicting the content of the message, discourse participants anticipate the main idea and speaker's goals beforehand. This apperception and anticipation construct variants of the right context in advance as a set of concepts. The variants evoke units in the mental lexicon that are relevant to the to-be-generated-content. Hence, the variant of the to-be-generated-content influences speech and text comprehension and production.

Reciting the poem of Korney Chukovsky mentioned above, LA replaced an old spider ('старичок-паучок') which captured the fly into its web with ((8) (10.2012)) a madcap-lad ('сорванец-молодеи'), owing to her apperception of the future events of the poem. The content of the poem were represented in her memory as a cloud; LA was able to extract a 'hero' from the cloud, but failed to recognize the right one. Thus, the substitution was triggered by the right context.

Associations to the individual experience and cultural stereotypes. Another type of substitution bears associations created by the interconnections of objects, actions and events in the individual's experience. The substitutes appear instead of some weird content that contradicts everyday routine and scripts typical of the culture. For example, a typical old woman in the Russian countryside works in her garden, cultivating some vegetables and fruits. According to that, LA recollected a line from the English ballad translated by Marshak as:

(9) (02.2013) Старушка пошла поливать огород (instead of продавать молоко)

The old woman went to water the garden (instead of to sell milk).

Associations based on contrast and contradictions. Substitutes semantically opposed to the target word are produced by a person with self-control or inhibitory control deficiency, or by an emotionally unstable person. LA described an inverse situation while reciting a poem by N. Rubtsov:

(10) (09.2013) Побежала коза в огород, А за ней потянулся народ, (instead of ей навстречу попался народ)

Ran the nanny goat in the garden, And after her followed people (instead of moved towards her) 
In (10) the substitution by the opposite describes the more typical script and eliminates the contradiction between the poem and life experience stored in the nondeclarative memory; LA 'polished' the lines.

\section{Substitution/paraphasias as peculiarities of speech deficit}

Indefinite pronouns as substitutions. AD patients produce more empty phrases and conjunctions than a patient with aphasia, including anomic aphasia (Nicholas, Obler, Albert, \& Helm-Estabrooks, 1985). The empty discourse generation reflects a naming deficit, as well as deficiencies in semantic programming of the utterance. Syntactic positions need to be filled in by words; however, it takes time to find a relevant word, so in fluent speech an indefinite pronoun appears as a filler of the position. LA switched to the pronouns when she failed to recollect a target word as an epithet in the Marshak's translation:

(11) (02.2013) к старушке какой-то щенок подошел (instead of веселый) to the old woman a puppy approached (instead of merry).

Meanwhile, in fiction and poetry indefinite pronouns are used as figures of speech. LA was able to play with pronouns the same way in the conversation, masking her memory loss and expressing her easy-going attitude in everyday routine:

(12) (09.2012) Я только что что-то куда-то убрала и хотела тебя об этом предупредить. Но пока шла, забыла - и что убрала, и куда. $B$ общем, если ты будешь что-то искать, то имей в виду, что оно где-то.

I have put away something somewhere just a minute ago and wanted to tell you about it. But I forgot what I have put away and where while I was coming here. In case you will look for something, you will find it somewhere.

Substitutions in phrasemes. Phrasemes are very sensitive to substitutions. The meaning of an idiom is not predictable on the basis of summarizing its words semes; the cultural tradition generates an additional meaning. The ability to process and to reproduce idioms along with other samples of the figurative language is considered to be a crucial skill of the healthy brain (Bohrn, Altman, \& Jacobs, 2012).

LA failed to reproduce or to complete idioms owing to the deficit of analytics and semantic processing. Looking into the fridge in their kitchen, the caregiver offered LA to complete the sentence with the idiom:

(13) (12.2012) В холодильнике продуктов кот... LA: наклевал (instead of наплакал).

Cat... the food in the fridge LA: nibbled a little (instead of shed a few tears $)^{10}$

10 The idiom means 'fridge is near empty'; the equivalent in English is 'next to nothing'. 
The relevant seme in the phonetically similar substitution expressed a small amount of something that was obvious in the situation. LA could not recollect the phraseme even in the friendly environment.

The AD patient's ability to handle the experience while processing the idiom depends on some unclear parameters of the current situation; the executive function needs an extra stimulus to work properly. In a dialogue, mild AD patients are spontaneously able to use idioms correctly, as LA did:

(14) (03.2012) Знаешь, делай отсюданоги. Мотай (instead of сматывай) удочки. И поскорее.

Do a bunk from here. Take to your heels. And do it faster.

Phonetic similarity of substitutions. Phonetic similarity appears to be an essential factor in lexical access, especially to the lexicon peripheries. We feel the phonetic frame of a target word, which includes both segmental and supersegmental features. The segmental and supersegmental similarity between the target word and its substitute plays an essential role; however, the frequency of the substitute is more important than the phonetic similarity. Some examples of LA's poem recitations prove the priority of the frequency:

(15) (04.2016) Открой сомкнуты небом (instead of негой $\check{\check{11}}^{11}$ взоры Open serried by the sky (instead of by bliss) gazes

Phonetic similarity with the context. Even the phonetic similarity itself is ambiguous. The quoted experimental studies provided examples of the similarity between a target and its substitutions, while sometimes the substitutions are similar to the context due to the consonance and alliteration. The obsessive iteration of sounds and syllables is considered as a paraphasia in speech disorders. In AD, the phonetic similarity becomes a hint for the lexical selection when the patient:

- Choose a substitution considering a semantic field and a phonetic frame of the target word, as in the case of TOT;

- Lose a semantic key to the target word and cannot catch a proper script sample in his / her everyday routine. Since the patient loses both paths to access the target word through verbal associations and life experience, the only path available to the patient is to follow the context.

LA demonstrated both ways to struggle against the speech errors and mistakes provoked by the memory loss. She replaced the target word by its phonetic similar, as well as hung upon the sounds of the context. The phonetic similar appeared as an association between a founder of the city of Rome and a resort town in Latvia:

(16) (08.2014) Но дней минувиих анекдоты От Юрмаль до наших дней... (instead of Ромула) But days past anecdotes from Jurmala to our days...(instead of Romulus)

11 Небом осcurs in the Poetry Corpus in 1004 sentences, негой - in 255 sentences only. 
Jurmala was one of LA's favorite resort towns when she lived in Saint Petersburg. Therefore, LA kept supporting consonants in her mind and searched in her vocabulary, making attempts to select a proper noun with the sequence '.r.m.l.', even though the attempt resulted in an ambiguous poetic line.

When access to the target is lost completely, a substitution repeats a phonetic chunk of the context. In poem recitation, it is natural to produce a rhyme by iteration of a previous word's final syllables, as LA did:

(17) (04.2015) ...Бранил Гомера, Робеспьера (instead of Феокрита) [He] scolded Homer, Robespierre (instead of Theocritus)

To be precise, it is important to mention that the substitution is reasonable, since the sentence with the substitute refers to a situation in which someone scolded two famous historical persons. Many substitutes in LA's speech and recitation were generated according to the phonemes in the left context. Thus, (16) represents a substitution similar to the target, while the substitution in (17) repeats the syllables of the left context.

Nonetheless, in everyday communication LA managed to play on iterations and phonetic similarity. She described the relationship between an interlocutress and her dog as:

(18) (10.2012) Он у тебя на поводке, а ты у него на поводу. You let your dog run on a leash, but it is the dog, which keeps you on a string.

The phonetic similarity to the context plays an essential role for AD patients when they struggle to access a lexeme in a semantic field connected to the meaning that is to be expressed in the utterance.

\section{Discussion}

\section{Classification of the substitutions and paraphasias}

Statistics of the substitutions. Our classification of the substitutions and paraphasias in the AD patient's speech is based on the semantic or associative connections and phonetic similarity with the target word. Semantic relations evoke Synonym, Hypernym / Category name, Co-hyponym and Hyponym as a substitution; Co-hyponyms of a target word result in paraphasias.

Associative connections (Association to the target, to the left context, to the right context, Associations with experience, Contrasts) provoke paraphasias, even in the case of the link to the target. The variety of phonetic similarity with the target / context manifests difficulties in processing semantics, weakening of semantic links, and restructuring of the mental lexicon. On the other hand, it also manifests as a lack of focus on the meaning of speech and inhibitory control. The total number of substitutions at the severe stage of the disease increased by a third. Table 1 provides data of the substitutions in poem recitation. 
For the statistics, we chose only transparent and clear cases without repetition of the same mistakes in the same poetic lines (as in (2)) $)^{12}$. Also, we avoided ambiguity of complex strategies in searching for a word. Thus, phonetic similarity is manifested in Table 1 as a pure case (see (15) - (17)). The phonetic similarity appears as a concomitant supporting feature for a synonym or an association substitution (see (4)) in $12.43 \%$ of all poem recitation records. So, the phonetically similar substitutions are close to $28 \%$ in total.

The difference in the distribution is statistically significant. Wilcoxon criterion $T=10.5, N=12^{13}, p<0.013$ (the signed-rank test for matched pairs) confirms strong dependence between substitution types and the stage of AD. Paraphasias became more frequent in severe AD; target words were substituted by their associations or similar sounding words. These types of paraphasias indicate a gap in the semantic representation. The patient did not remember the meaning of the target word, and operated by some fuzzy associations. Context provides priming for the substitutions in $\mathrm{AD}$ at all stages. At the severe stage of the disease, the patient's ability to focus and overcome interference of the context was exhausted that reflects the regress of the inhibitory function.

Table 1. Percentage of the different substitution types in the poem recitation

\begin{tabular}{lcccccccc}
\hline $\begin{array}{l}\text { The stage } \\
\text { of AD }\end{array}$ & $\begin{array}{c}\text { Syno- } \\
\text { nym }\end{array}$ & $\begin{array}{c}\text { Hyper- } \\
\text { nym / } \\
\text { Cate- } \\
\text { gory } \\
\text { name }\end{array}$ & $\begin{array}{c}\text { Co- } \\
\text { hypo- } \\
\text { nym / } \\
\text { Hypo- } \\
\text { nym }\end{array}$ & $\begin{array}{c}\text { Associa- } \\
\text { tion } \\
\text { (target) }\end{array}$ & $\begin{array}{c}\text { Asso- } \\
\text { cia- } \\
\text { tion } \\
\text { (con- } \\
\text { text) }\end{array}$ & $\begin{array}{c}\text { Associa- } \\
\text { tion } \\
\text { (expe- } \\
\text { rience) }\end{array}$ & $\begin{array}{c}\text { Cont- } \\
\text { rast }\end{array}$ & $\begin{array}{c}\text { Phonetic } \\
\text { simi- } \\
\text { larity }\end{array}$ \\
\hline $\begin{array}{l}\text { Moderate } \\
(\mathbf{2 0 1 2 - 2 0 1 3 )}\end{array}$ & 5.06 & 1.12 & 5.06 & 5.06 & 12.92 & 5.06 & 3.36 & 5.00 \\
$\begin{array}{l}\text { Severe } \\
(\mathbf{2 0 1 4 - 2 0 1 6 )}\end{array}$ & 3.37 & 0.56 & 1.69 & 23.03 & 12.36 & 4.49 & 0.56 & 10.67 \\
$\begin{array}{l}\text { Total } \\
(\mathbf{N}=\mathbf{1 7 8})\end{array}$ & 8.43 & 1.68 & 6.75 & 28.09 & 25.28 & 9.55 & 3.92 & 15.67 \\
\hline
\end{tabular}

Note: The sum of the third line figures does not match $100 \%$, because the table does not include pronouns.

Deep analysis of the classification. Semantic similarity results in substitutions from the target word's semantic category. If the target is replaced by a Co-hyponym or Hyponym of its own, the substitution could be identified as paraphasia, since it causes changes in the sentence proposition. Due to their diversity, associative connections provide a lot of variants to substitute the target. Represented in the mental lexicon as units of the network, the variants compete in different aspects, as it is described in connectionist models of the mind (McClelland \& Cleeremans, 2009). In AD, the interconnections in

12 The unit of analysis is a word (lexeme), not a word usage.

13 Twelve pairs of indicators equal the number of the substitutions and paraphasias categories. 
the brain are damaged, so the competition conforms to conditions in which it is hard to neglect the current context and environment because inhibitory control is weakened. Therefore, the current context as natural priming and the individual's experience stored in nondeclarative memory bring the strongest impact. Associations represent paraphasias based on different links between the target and the context as well. The associations come from the individual experience, replacing the target and creating a new content, which reflects important personal events and images.

Phonetic similarity provides a key for a substitution when a patient loses the semantic features of a target word. Meanwhile, the syntactic role of the word is clear; however, syntactic hints are insufficient for extracting a lexical match from the mental lexicon. Two systems of segmental priming and supersegmental priming appear to work independently, at least in reading (Sulpizio \& Kinoshita, 2016). As far as we consider, the systems also work independently in poem recitation since the supersegmental priming results in accurate mapping to the rhythm and rhyme.

Sounds repletion, syllabic structure, and length of the word play significant role in the process of lexical retrieval in the case of TOT (Schwartz \& Metcalfe, 2011). The same factors determined the selection of the substitute in LA's speech, though she was not aware of the substitution itself. The phonetic similarity between the target and its substitute was important to her, but phonetic parallels in the context played a more essential role. Thus, the way to access a forgotten word through the supporting sounds regularly appears in speech / mental disorders.

In the process of speech production, the most powerful factor is the frequency of words competing in the lexical selection process (Schmalz, Treccani, \& Mulatti, 2015). The frequency of the substitute is more important than the degree of its phonetic similarity.

As AD progressed, the percentage of the paraphasias increased, and the percentage of substitutes in the patient's poem recitation matching the target meaning decreased. Based of the classification, we can explain the most important type of semantic similarity for substitutions in AD. The substitutions belong to the same or lower hierarchy level in comparison with the target word. However, associative connections win the competition to become articulated as a target word substitute in the AD patient's speech. Natural priming from the context interferes in the process of lexical choice, redirecting it from the conscious selection of the target word to concomitant associations. All types of substitutions and paraphasias in $\mathrm{AD}$ patients match the diversity of well-known mistakes in everyday spontaneous conversations that children and adults produce from time to time. Meanwhile, individuals with AD regularly generate diversity of mistakes.

The model of substitutions in AD includes 5 features: a substitution (a) as usual, belongs to the same grammatical class and has the same grammatical markers as the target word; (b) it is frequent in the particular discourse; (c) it is 
connected to the current context or the target word by associations; (d) it relates to the speaker's life experience and culture; and (e) it is phonetically similar to the context.

\section{Speech failures in AD}

Masking strategies in everyday communication. To mask the damage, LA worked out several strategies. Her spontaneous conversation presented the best of her communication skills and linguistic ability (compared to the poem recitations). First of all, she always appealed to the sense of humor when interpreting her mistakes and errors in speech behavior. LA was always aware of her interlocutors' interests and sentiments; if the interaction flowed easily, the communication evoked a lot of positive emotions, enhancing memory ${ }^{14}$. LA was competent enough to play on words and idioms at the moderate and even at the severe stage of the disease:

(19) (03.2016) Куда мы идем? - Наверх, на второй этаж (в клинике). Будем на всех сверху плевать?

Where we are going? - Upstairs, to the second floor (in the hospital). To spit from there (= to show we do not care about all of them)?

Secondly, the patient tried to overcome the communication problems through her empathy. The substitutions and paraphasias gave a chance to express her willingness to communicate. The following dialogue reflects her attitude to the disease and the communicative troubles she had been suffering from for years:

(20) (10.2012) Ть мне один и тот же вопрос задаешь пятый раз подряд в течение десяти минут. Пожалей меня. Неужели ты не можешь поднапрячься и хотя бы попытаться запомнить ответ? - A я задаю вопрос вовсе не для того, чтобы выслушать ответ. Я задаю вопрос ради коммуникаиии.

You have asked me the same question for the fifth time in ten minutes. Take a pity on me. Would you mind to exert yourself to remember the answer? - But I am far from hearing the answer when I am asking you. I am asking you on behalf of the communication itself.

The case study compared to experiment data. Researchers consider speech failures in $\mathrm{AD}$ to be a manifestation of the impairment in different cognitive domains. The damage is widespread; the neuron network fails to provide encoding, retrieval, and coordination of different operations in the domains. Regarding the $\mathrm{AD}$ patients' speech comprehension and production, the authors of the studies found several specific features of the patients' speech based on the results of the different tests. The features reflect the anomia, but the loss of the semantic information is selective: familiarity with the topic in the life experience facilitates word finding (Bucks, Singh, Cuerden, \& Wilcock, 2000).

14 The importance of positive emotions for memorizing in AD was discussed in (Kumfor, Hodges, \& Piguet, 2014) 
The relatively spared nondeclarative implicit memory provides access to life events, supporting processing of perceptual information (op.cit.). All of the features are relevant to our patient's communicative behavior.

1. Producing more empty phrases and conjunctions (Nicholas, Obler, Albert, $\&$ Helm-Estabrooks, 1985). Indefinite pronouns and general names occur as substitutions for the target word in everyday conversations, according to the well-known peculiarity of the AD patients' speech (Bridges \& Van Lancker Sidtis, 2013). Our patient used indefinite pronouns in spontaneous speech, sometimes pretending to generate a figure of speech, making an attempt to mask her word recollecting failures. However, LA was successful in avoiding empty phrases until late 2015, when her condition deteriorated noticeably.

2. Syntactic and phonemic processes are relatively preserved in AD (Buck, Singh, Cuerden, \& Wilcock, 2000; Martyr, Boycheva, \& Kudlicka, 2017). The patients produce correct syntactic constructions, using words in syntactic positions according to the sentence meaning until the severe stage of the disease. LA also filled in the substitutions relevant to her experience and cultural context, being sensitive to syntax and the discourse peculiarities.

3. Specific problems in processing the figurative language (Bohrn, Altman, \& Jacobs, 2012). AD patients failed to correspond the meaning of the idiomatic phrase with a relevant picture or a one-word description; they understood the phraseme literally / by semantic associations to words from the idiom without processing sentential meaning (Rassiga, Lucchelli, Crippa, \& Papagno, 2009, p. 409). The patients also manifested significant problems selecting the correct abstract word to explain even familiar proverbs (Chapman, Ulatowska, Franklin, Shobe, Thompson, \& McIntire, 1997). Since AD damages the cortex, the patients are impaired in different cognitive domains; they lose the ability to grasp the idiom holistically on the ground of their own communicative and cognitive experience when they performed the tests. LA failed to complete idioms, but was sporadically able to generate idioms in conversations with her loved ones.

4. The influence of poor semantic processing and weak executive functioning on the verbal communication in general. Individuals with AD overuse cliché (Bridges \& Van Lancker Sidtis, 2013) because a cliché penetrates into the speech program automatically as a filler of a syntactic position. The increase of the associations in naming tests and spontaneous speech reflects the poor semantics, insofar as associations replace semantic relations and accuracy of the lexical selection. Word connections in the lexicon periphery are jumbled and fuzzy, and the indistinctness makes 
access to a particular word more difficult. Thus, the associations break into the semantic programming of the utterance, interrupting the lexical selection instead of mediating it (Achenson, Rostlie, \& MacDonald, 2010).

The difference between LA's speech and the verbal behavior of the AD patients examined in the publication reflects the contribution of her education in Philology and Linguistics. Her semantic and executive functioning became poorer in comparison with her abilities before the disease. However, even in the moderate AD, LA was able to find semantically sensible substitutions of target words in poems.

\section{Conclusions}

Our case study of the AD patient's speech shows the specific verbal behavior of a person who suffered $\mathrm{AD}$ for more than seven years. The specificity reflects the differences in lexical retrieval and selection during recitation of the poems and in everyday conversation. The strategies used to recollect the target word in the poem are based on the text features first of all; when the semantics of the line, rhythm, and rhyme fail to facilitate the search for the target word, the patient switched to her real-life and cultural experience. On the contrary, in everyday communication the emotions and interactions with the interlocutors provided the patient with the grounds for the lexical selection. The patient felt a lot of difficulties selecting the linguistic units. However, she was able to mask her errors and overcome the troubles due to humor, reliance on cooperation and a friendly environment. The substitutions penetrated her speech when the support of the implicit memory became insufficient.

\section{Acknowledgements}

We would like to thank the neuropathologists and neurologists of Atos Klinik, Heidelberg, Germany, who provided us with the patient's hospital chart, for their kind assistance.

We are also grateful to the reviewers of the manuscript for their very helpful remarks allowing us to reconsider the objective and notably improve our manuscript.

\section{References}

Achenson D. J., Rostlie B. R., MacDonald M. C. (2010). The Interaction of Concreteness and Phonological Similarity in Verbal Working Memory. Journal of Experimental Psychology: Learning, Memory, and Cognition, 36(1), 17-36. doi: 10.1037/a0017679 
Baayen, R. H., Milin, P. and Ramscar, M. (2016). Frequency in lexical processing. Aphasiology, 30(11) 1174-1220. doi: 10.1080/02687038.2016.1147767

Bohrn I. C., Altman U., Jacobs A. M. (2012). Looking at the brains behind figurative language - a quantitative meta-analysis of neuroimaging studies on metaphor, idiom, and irony processing. Neuropsychologia, 50, 2669-2683 doi: 10.1016/j.neuropsychologia.2012.07.021

Bridges, K. A., Van Lancker Sidtis, D. (2013). Formulaic language in Alzheimer's disease. Aphasiology, 27(7), 799-810. doi: 10.1080/02687038.2012.757760

Brown, R., McNeill, D. (1966). The "tip of the tongue" phenomenon. Journal of Verbal Learning and Behavior, 5(4), 325-337. doi: 10.1016/S00225371(66)80040-3

Bucks, R. S., Singh, S., Cuerden, J. M., \& Wilcock, G. K. (2000). Analysis of spontaneous, conversational speech in dementia of Alzheimer type: Evaluation of an objective technique for analyzing lexical performance. Aphasiology, 14(1), 71-91. doi: 10.1080/026870300401603

Cera, M. L., Ortiz, K. Z., Bertolucci, P. H. F., \& Minett, T. S. C. (2013). Speech and orofacial apraxias in Alzheimer's disease. International Psychogeriatrics, 25(10), 1679-1685. doi: 10.1017/S1041610213000781

Chapman, S.B., Ulatowska, H.K., Franklin, L.R., Shobe, A.E., Thompson, J.L. \& McIntire D.D. (1997). Proverb Interpretation in Fluent Aphasia and Alzheimer's disease: Implications beyond Abstract Thinking. Aphasiology, 11(4-5), 337 - 350. doi: 10.1080/02687039708248475

Ferraro, K. F., \& Wilmoth, J. M. (Eds.). (2013). Gerontology: Perspectives and issues. Forth Edition. New York, NY: Springer Publishing Company.

Jellinger, K. A. (2013). Pathology and pathogenesis of vascular cognitive impairment - a critical update. Frontiers in Aging Neuroscience, 5(17). doi: 10.3389/fnagi.2013.00017

Kumfor, F., Hodges, J. R., \& Piguet, O. (2014). Ecological Assessment of Emotional Enhancement of Memory in Progressive Nonfluent Aphasia and Alzheimer's Disease. Journal of Alzheimer's Disease, 42(1), 201-210. doi 10.3233/JAD-140351

Martyr, A., Boycheva, E., \& Kudlicka, A. (2017). Assessing inhibitory control in early-stage Alzheimer's and Parkinson's disease using the Hayling Sentence Completion Test. Journal of Neuropsychology. doi: 10.1111/jnp.12129

McClelland, J. L., Cleeremans, A. (2009). Connectionist models. In: T. Byrne, A. Cleeremans \& P. Wilken, (Eds.). Oxford companion to consciousness. New York, NY: Oxford University Press.

Nicholas, M., Obler, L. K., Albert, M. L., Helm-Estabrooks, N. (1985). Empty speech in Alzheimer's disease and fluent aphasia. Journal of Speech, Language, and Hearing Research, 28(3), 405-410.

Rassiga, C., Lucchelli, F., Crippa, F., Papagno, C. (2009). Ambiguous idiom comprehension in Alzheimer's disease. Journal of Clinical and Experimental Neuropsychology. 31(4), 402-411. doi: 10.1080/13803390802220019 
Schecker, M., Kochler, C., Schmidtke, K., \& Rauh, R. (2014). Are there any connections between language deficits and cognitive slowing in Alzheimer's disease? Dementia and geriatric cognitive disorders extra, 4(3), 442-449. doi: 10.1159/000368317

Schmalz, X., Treccani, B., and Mulatti, C. (2015) Distinguishing Target From Distractor in Stroop, Picture-Word, and Word-Word Interference Tasks. Frontiers in Psychology, 6(1858). doi: 10.3389/fpsyg.2015.01858

Schwartz B., Metcalfe J. (2011). Tip-of-the-tongue (TOT) states: Retrieval, behavior, and experience. Memory \& Cognition, 39(5), 737-749.

Silagi, M. L., Bertolucci, P. H. F. \& Ortiz, K. Z. (2015) Naming ability in patients with mild to moderate Alzheimer's disease: what changes occur with the evolution of the disease? Clinics, 70(6). doi: http://dx.doi.org/10.6061/ clinics/2015(06)07.

Slimani, T. (2013). Description and evaluation of semantic similarity measures approaches. International Journal of Computer Applications, 80(10), 25-33. doi: $10.5120 / 13897-1851$

Stuart, G., \& Hulme, C. (2000). The effects of word co-occurrence on short-term memory: Associative links in long-term memory affect short-term memory performance. Journal of Experimental Psychology: Learning, Memory, and Cognition, 26(3), 796-802. doi: 10.3389/fpsyg.2016.00661

Sulpizio, S., \& Kinoshita, S. (2016). Bridging Reading Aloud and Speech Production. Frontiers in Psychology, 7: 661. doi: 10.3389/fpsyg.2016.00661

Vitevitch, M. S., \& Luce, P. A. (2016). Phonological neighborhood effects in spoken word perception and production. Annual Review of Linguistics, 2, 75-94.

Vygotsky L. S. (1934). Mysl“ $i$ slovo. [Thought and Word].

Zwaan, R. A. (2016). Situation models, mental simulations, and abstract concepts in discourse comprehension. Psychonomic Bulletin \& Review, 23(4), 1028-1034. doi: 10.3758/s13423-015-0864-x 